\title{
Influence of Spatial Precipitation Sampling on Hydrological Response at the Catchment Scale
}

\author{
Domenico Caracciolo ${ }^{1}$; Elisa Arnone, Ph.D. ${ }^{2}$; and Leonardo Valerio Noto, Ph.D. ${ }^{3}$
}

\begin{abstract}
Retrieving precipitation data from a rain gauge network is a classical and common practice in hydrology and climatology. These data represent the key input in hydrological modeling to reproduce, for example, the characteristics of a flood phenomenon. The accuracy of the model results is strongly dependent on the consistency of the monitoring network in terms of spatial scale, i.e., network density and location of the rain gauges and time resolution. In this context, several studies have been carried out to analyze how the rainfall sampling influences the estimation of total runoff volume. The aim of this paper is to use a physically based and distributed-parameter hydrologic model to investigate how the number and the spatial distribution of a rain gauge network influence the estimation of the hydrograph and its characteristics in conjunction with different spatial and temporal characteristics of rainfall forcing and different soil-type characteristics. The TIN-based real-time integrated basin simulator (tRIBS) hydrologic model was used to simulate hydrologic response at Baron Fork Basin, Oklahoma. Downscaled next-generation radar (NEXRAD) measurements were assumed to represent the true precipitation distribution over the basin. Additional precipitation fields have been derived from the interpolation of eight fictitious rain gauges randomly placed in the area. The hydrological response from tRIBS that is driven by these precipitation fields has been compared with the response of the model forced with NEXRAD precipitation. The analysis has been carried out assuming first simplified spatial distributions of soil characteristics and then the real soil-type distribution. Results have shown the dependence of the best rain gauges configuration for the estimation of runoff on the spatiotemporal characteristics of storm events and the soil-type distribution. DOI: 10.1061/(ASCE)HE.1943-5584.0000829. () 2014 American Society of Civil Engineers.
\end{abstract}

Author keywords: Rain gauge network; Hydrologic model.

\section{Introduction}

In the past years, numerous field experiments have revealed that most of the hydrological processes occurring in a basin are characterized by considerable spatial variability (Schuurmans et al. 2007). In hydrological modeling, these processes are most likely described by the spatially distributed approaches, whose efficiency is often compromised by large uncertainties in spatially distributed input variables. Particularly, rainfall is often defined as the key variable in such hydrological systems because of its crucial role in determining surface processes.

Precipitation is governed by complicated physical processes that are inherently nonlinear and extremely sensitive (Bardossy et al. 1992); it is significantly variable in space and time within a catchment (Krajewski et al. 2003) and the spatial variability has a dominant impact on runoff modeling (Bell et al. 2000). The time-spatial variability clearly affects every method of rainfall estimation and

${ }^{1}$ Ph.D. Student, Dipartimento di Ingegneria Civile, Ambientale, Aerospaziale, dei Materiali (DICAM), Università degli Studi di Palermo, Palermo 90128, Italy (corresponding author). E-mail: domenico .caracciolo@unipa.it

${ }^{2}$ Dipartimento di Ingegneria Civile, Ambientale, Aerospaziale, dei Materiali (DICAM), Università degli Studi di Palermo, Palermo 90128, Italy. E-mail: elisa.arnone@unipa.it

${ }^{3}$ Assistant Professor, Dipartimento di Ingegneria Civile, Ambientale, Aerospaziale, dei Materiali (DICAM), Università degli Studi di Palermo, Palermo 90128, Italy. E-mail: leonardo.noto@unipa.it

Note. This manuscript was submitted on August 17, 2012; approved on April 4, 2013; published online on April 5, 2013. Discussion period open until August 1, 2014; separate discussions must be submitted for individual papers. This paper is part of the Journal of Hydrologic Engineering, Vol. 19, No. 3, March 1, 2014. (C) ASCE, ISSN 1084-0699/2014/3-544$553 / \$ 25.00$. influences the design of a rain gauge network (Sun et al. 2002). Rain gauges provide a point estimation of rainfall, which is then used to obtain a spatial distribution of precipitation over the catchment through spatial interpolation techniques. However, if the rain gauge network density is low, or the distribution of gauges and the interpolated methods are not correct, the rainfall field obtained may be affected by a large estimation error that is transferred, often amplified, to the runoff through the hydrological model.

For such a reason, design of rain gauge networks both in terms of density (number of rain gauges), structure (location of a single rain gauge), and temporal resolution has been an issue widely investigated in scientific literature to better understand its implications in hydrological modeling, e.g., its influence on basin discharge (Krajewski et al. 1991; St-Hilarie et al. 2003; Meselhe et al. 2009).

Starting from the pioneer works of Eagleson and Shack (1966) and Eagleson (1967a, b), a number of studies have been developed, which basically differ in the hydrological model used (distributed or lumped, physically based, or black-box), the temporal scale (event scale or continuous simulations), the basin spatial scale, and the assessed output variable (volume of runoff, peak runoff, time to peak).

Wilson et al. (1979) performed the analysis at event scale and found that the spatial distribution and the accuracy of the rainfall input influence the estimation of the volume of storm runoff, peak runoff, and time-to-peak simulated by the hydrological model.

Krajewski et al. (1991) forced a physically based distributedparameter hydrologic model on a small basin with synthetic rainfall to investigate the effect of different spatial and temporal rainfallinput sampling density on the model response at the event scale. The results indicated higher sensitivity of basin response with respect to the rainfall data temporal resolution rather than the spatial resolution. 
Obled et al. (1994) used the semidistributed version of TOPMO$D E L$ with different patterns of rainfall point data given by five and 21 rain gauges, showing that although the use of a greater number of rain gauges was irrelevant to the estimation of precipitation, the small differences obtained became significant when the response was assessed in terms of runoff. In fact, the increase of the number of rain gauges caused an elevated improvement in the estimation of both runoff and flood peak.

Faurès et al. (1995), through analysis at the event scale, demonstrated that the uncertainty in runoff estimation is strongly related to the number of gauges providing the input data. In case of increased spatial rainfall gradients, the location of the gauge also becomes a crucial parameter in the modeling of the storm hydrograph.

Another important contribution by Lopes (1996) indicated that the relative importance of the location of a specific gauge in describing the rainfall field may change with spatial and temporal storm characteristics, demonstrating also the influence of the spatial arrangement of single rain gauges on catchment response prediction.

The correlation between the scale of the basin and the effect of rain gauges spatial density is explicitly studied in the work of Arnaud et al. (2002), showing that this correlation changes in the case of very extreme events. The development of spatially distributed models has encouraged the analysis of the effect of rainfall spatial variability on different distributed hydrological variables such as soil moisture, groundwater level, and discharge. As an example, Schuurmans et al. (2007) showed that the spatial variability of daily rainfall has a major effect on discharge and spatial distribution of groundwater level and soil moisture content of the catchment. More recently, studies based on continuous simulations have also been carried out (Bardossy et al. 2008), confirming that an excessive reduction of rain gauges, up to a certain threshold number, makes model performances worse. Meselhe et al. (2009), using a physically based and conceptual hydrologic model, showed that an increase in the rain gauge density or the rainfall data temporal resolution caused a significant improvement of the hydrograph estimation.

The more recent physically based and spatial distributed hydrological models allow for the investigation of further important issues, such as the analysis of how the different soil-type characteristics may influence the design of a rain gauge network for the estimation of the discharge hydrograph. Indeed, because the different hydrological properties directly control the rainfall-runoff transformation, it becomes significant to determine how the spatial correlation between different precipitation fields and soil-type distribution influence the hydrological response.

In this regard, the present study analyzes the influence of the rain gauge network configuration in terms of number and spatial distribution on the estimation of the discharge hydrograph, explicitly taking into account the soil spatial distribution within the basin differently from previous studies. The work is carried out by applying a physically based distributed-parameter hydrologic model to the Baron Fork Watershed in Oklahoma. The analysis is performed at the event scale by considering nine precipitation events with different spatiotemporal characteristics, all occurring during 1998. The influence of the rain gauge network configuration on the estimation of the runoff is thus assessed by analyzing the relationship between spatial distribution of rainfall and soil-type patterns simultaneously within the study area. First, the analysis assumes some simplified and fictitious spatial distributions of soil characteristics and then the real spatial distribution of soil types. In this way, the dependence of the best rain gauge configuration on the soil-type distribution is investigated as well as the influence of the spatiotemporal characteristics of storm events on the assessment of the rain gauge network performance.

\section{Model}

The TIN-based real-time integrated basin simulator (tRIBS) (Ivanov et al. 2004a, b) is the model used in this study. tRIBS explicitly considers the spatial variability in precipitation fields and land-surface descriptors and is capable of solving basin hydrology at very fine temporal (hourly) and spatial (10-100 m) scales. An adaptive multiple resolution approach, based on triangulated irregular networks (TINs), is used to represent the complexity of the simulation domain, allowing a significant reduction of the number of the computational model elements. The tRIBS model currently includes a variety of hydrologic processes, as briefly described in Noto et al. (2008). Interested readers are referred to Ivanov et al. (2004a, b) for details concerning the model structure, parameterization, forcing, and testing for a series of real basins.

\section{Case Study}

\section{Basin Description}

The study area selected for the analysis is the Baron Fork Basin, where the tRIBS model has been successfully calibrated and verified by Ivanov et al. (2004a, b).

The basin, located in northeastern Oklahoma, is $800 \mathrm{~km}^{2}$ in size, and its elevation is between 200 and $600 \mathrm{~m}$ above mean sea level. Most of the basin is characterized by steep slopes (15-40\%) with gently rolling relief at the basin headwater (east) and rugged terrain in its lower areas (west) (Fig. 1). Vegetation covers approximately $52 \%$ of the area with deciduous and evergreen forests and $46 \%$ with croplands and orchards. The surface soil texture is primarily silt-clay (47\%), sandy-clay-loam (40\%), and loam (13\%). For a more detailed description of the basin, interested readers can refer to Ivanov et al. (2004a, b) and Liuzzo et al. (2010).

\section{Data}

\section{Precipitation}

The spatial distribution of precipitation fields over the basin has been obtained by the next-generation weather radar (NEXRAD) system, available for the study area (Vivoni et al. 2006) in the form of hourly NEXRAD 4-km gridded estimates. These precipitation fields have been used both to directly force

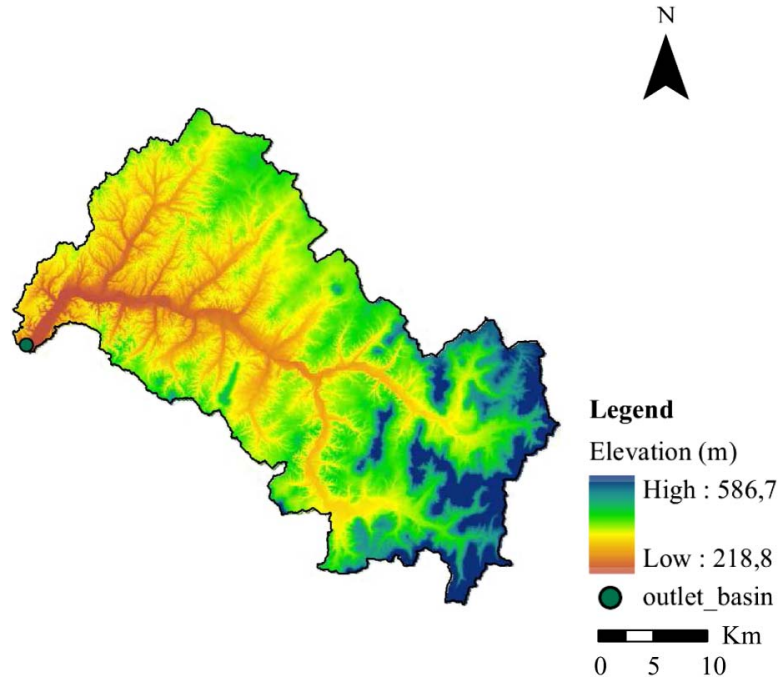

Fig. 1. DEM of the Baron Fork Basin 
Table 1. Rainfall Features for Each Event

\begin{tabular}{|c|c|c|c|c|c|c|c|c|c|}
\hline \multirow[b]{2}{*}{ Event ID } & Start event & End event & \multirow{2}{*}{$\begin{array}{l}\text { Duration } \\
\text { (h) }\end{array}$} & \multirow{2}{*}{$\begin{array}{c}\text { Total } \\
\text { rainfall }(\mathrm{mm})\end{array}$} & \multirow{2}{*}{$\begin{array}{c}i_{m} \\
(\mathrm{~mm} / \mathrm{h})\end{array}$} & \multirow{2}{*}{$\begin{array}{c}i_{m, \text { peak }} \\
(\mathrm{mm} / \mathrm{h})\end{array}$} & \multirow[b]{2}{*}{$\mathrm{COV}_{S}$} & \multicolumn{2}{|c|}{ Classification } \\
\hline & \multicolumn{2}{|c|}{ Date (month/day); time (hrs) } & & & & & & $\overline{i_{m}}$ & $\overline{\mathrm{COV}_{S}}$ \\
\hline $\mathrm{Hh}$ & $11 / 10 ; 0400$ & $11 / 10 ; 0900$ & 5 & 15.47 & 3.09 & 13.42 & 0.60 & $\mathrm{H}$ & $\mathrm{h}$ \\
\hline $\mathrm{Hm}$ & 01/04; 0300 & $01 / 05 ; 1800$ & 39 & 109.97 & 3.05 & 18.32 & 0.26 & $\mathrm{H}$ & $\mathrm{m}$ \\
\hline $\mathrm{Hl}$ & $10 / 05 ; 0700$ & $10 / 06 ; 1200$ & 29 & 101.18 & 3.49 & 20.13 & 0.12 & $\mathrm{H}$ & 1 \\
\hline $\mathrm{Mh}$ & 05/07; 0000 & 05/07; 0700 & 7 & 10.89 & 1.56 & 7.21 & 0.63 & M & $\mathrm{h}$ \\
\hline $\mathrm{Mm}$ & 12/06; 2000 & $12 / 07 ; 0000$ & 4 & 6.09 & 1.52 & 4.61 & 0.44 & M & $\mathrm{m}$ \\
\hline Ml & $09 / 12 ; 2000$ & $09 / 15 ; 2200$ & 74 & 116.11 & 1.73 & 15.45 & 0.12 & M & 1 \\
\hline $\mathrm{Lh}$ & $08 / 19 ; 1800$ & $08 / 20 ; 0100$ & 7 & 9.44 & 1.35 & 3.04 & 0.92 & $\mathrm{~L}$ & $\mathrm{~h}$ \\
\hline $\mathrm{Lm}$ & 06/18; 1000 & 06/18; 1900 & 9 & 8.91 & 0.99 & 2.31 & 0.45 & $\mathrm{~L}$ & $\mathrm{~m}$ \\
\hline L1 & $03 / 17 ; 0600$ & $03 / 17 ; 1800$ & 12 & 9.27 & 0.77 & 2.22 & 0.22 & $\mathrm{~L}$ & 1 \\
\hline
\end{tabular}

the hydrological model and to provide precipitation data sampled by fictitious rain gauge networks as described in "Assumptions and Simulations."

Following the approach used by many authors, the analysis of the effect of the rain gauge position has been performed at the event scale. Nine precipitation events that occurred during 1998 were chosen and classified as a function of their average intensity and spatial variability. This allowed for considering the precipitation characteristics on the influence of precipitation sampling on the hydrological response. The nine events were chosen according to the average, in time and space, of precipitation event intensity $i_{m}$ classified as high $(\mathrm{H})\left(i_{m}>2.5 \mathrm{~mm} / \mathrm{h}\right)$, medium $(\mathrm{M})$ $\left(1.5 \mathrm{~mm} / \mathrm{h}<i_{m}<2.5 \mathrm{~mm} / \mathrm{h}\right)$ and low (L) $\left(i_{m}<1.5 \mathrm{~mm} / \mathrm{h}\right)$, and to the spatial variability of the average of rainfall evaluated in terms of coefficient of variation $\mathrm{COV}_{S}$ (i.e., the ratio between the standard deviation of the mean intensity grid and the spatial average value of the same grid) ranked as high (h) $\left(\mathrm{COV}_{S}>0.5\right)$, medium (m) $\left(0.25<\mathrm{COV}_{S}<0.5\right)$ and low (1) $\left(\mathrm{COV}_{S}<0.25\right)$. Subjective ranges of the two classifications were chosen taking into account only the events that occurred in the basin during 1998.

The primary features of the nine events and the classification on the basis of precipitation intensity $\left(i_{m}\right)$ and coefficient of variation $\left(\mathrm{COV}_{S}\right)$ are summarized in Table 1 , which reports the ID event, the two-letter code in which the first capital letter denotes average intensity class ( $\mathrm{H}$ or $\mathrm{M}$ or $\mathrm{L}$ ) and the second small letter denotes the spatial variability class (h or $\mathrm{m}$ or $\mathrm{l}$ ), start event and end event date and hours, event duration $(\mathrm{h})$, total event rainfall $(\mathrm{mm})$, precipitation average intensity $i_{m}(\mathrm{~mm} / \mathrm{h})$, precipitation average intensity peak $i_{m \text {,peak }}(\mathrm{mm} / \mathrm{h})$, spatial variability of precipitation in terms of coefficient of variation $\mathrm{COV}_{S}$, and classification of the events as a function of the $i_{m}$ and $\operatorname{COV}_{S}$ values.

Fig. 2 describes the spatial pattern of the precipitation average intensity for each event. The range of event duration is from $4 \mathrm{~h}$ (event $\mathrm{Mm}$ ) to $74 \mathrm{~h}$ (event $\mathrm{Ml}$ ) and the total event rainfall amount is between $6.09 \mathrm{~mm}$ (event $\mathrm{Mm}$ ) and $116.11 \mathrm{~mm}$ (event $\mathrm{Ml})$. Event $\mathrm{Hl}$ shows the greatest average precipitation intensity $\left(i_{m}=3.49 \mathrm{~mm} / \mathrm{h}\right)$, the greatest average intensity peak $\left(i_{m \text {,peak }}=\right.$ $20.13 \mathrm{~mm} / \mathrm{h}$ ), and the lowest precipitation spatial variability $\left(\mathrm{COV}_{S}=0.12\right)$, whereas event $\mathrm{Ll}$ has the lowest average precipitation intensity $\left(i_{m}=0.77 \mathrm{~mm} / \mathrm{h}\right)$ and the lowest average intensity peak $\left(i_{m \text {,peak }}=2.22 \mathrm{~mm} / \mathrm{h}\right)$ and event Lh has the greatest spatial variability $\left(\mathrm{COV}_{S}=0.92\right)$.

\section{Soil-Type Distribution}

Simulations have been performed considering first two synthetic configurations with a single soil-type [silty-clay (c) at low permeability and sandy-clay-loam (s) at high saturated hydraulic conductivity coefficient] and then using two synthetic configurations of the same two soil-types distributed differently over the basin: silty-clay upstream the basin and sandy-clay-loam downstream

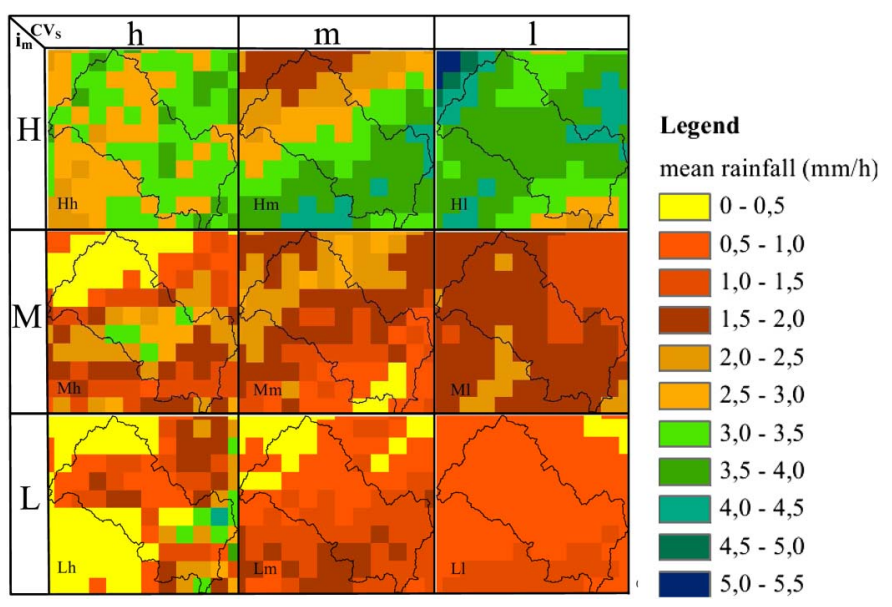

Fig. 2. Spatial pattern of average precipitation intensity for each event; events with the same average intensity class $(\mathrm{H}, \mathrm{M}$, or L) are in the same row, whereas events with the same coefficient of variation class (h, $\mathrm{m}$, or $\mathrm{l}$ ) are in the same column

the basin (cs) and vice-versa (sc) (Fig. 3). The two chosen soiltypes (silty-clay and sandy-clay-loam), besides belonging to the true soil-types distribution, have been selected because they are representative of substantially different hydrological soil properties. Finally, the true spatial distribution of soil types (r) with three soil types has been considered. The soil-type hydrologic parameters used by the tRIBS model are shown in Table 2 .

\section{Assumptions and Simulations}

To carry out all the simulations described above, the following assumptions have been made:

- The NEXRAD radar measurements are assumed to be representative of the true precipitation distribution; because rainfall exhibits considerable heterogeneity at smaller scales than those characterizing NEXRAD $(4 \mathrm{~km})$, the spatial resolution of this true precipitation has been increased to $1 \mathrm{~km}$ through a multiscale disaggregation method (Perica and Foufoula-Georgiou 1996). This method has the capability to statistically reproduce the rainfall variability at different scales and is conditioned on large-scale rainfall statistics. It is based on two tested hypotheses: first, the standardized rainfall fluctuations are characterized by simple scaling; and second, the statistical scaling parameters of these fluctuations can be related to the convective available potential energy (CAPE).

- The hydrological response from the tRIBS model forced with disaggregated NEXRAD precipitation has been assumed as true 

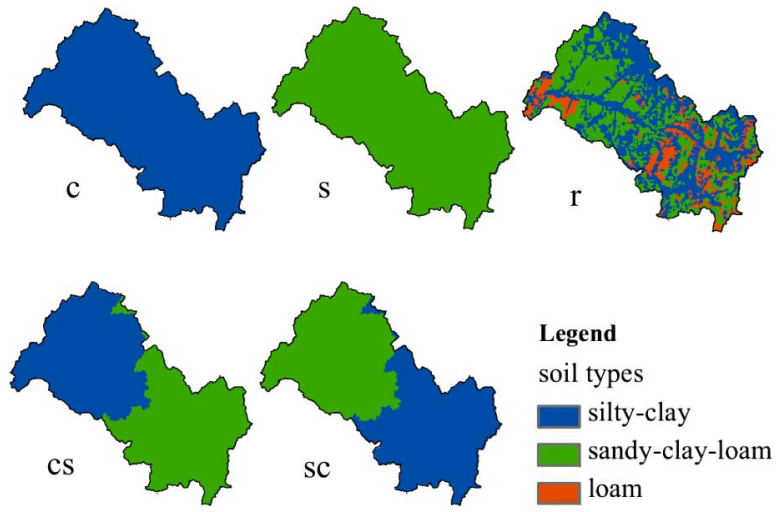

Fig. 3. Configurations of soil-type distribution used in the analysis

hydrological response of the basin (simulation zero) and is used as a reference for the other simulations.

- Eight fictitious rain gauges have been randomly distributed in the basin (Fig. 4) by placing four rain gauges approximately downstream (rain gauges 1-4) and four approximately upstream (rain gauges 5-8); upstream and downstream subbasins have been approximately identified as a function of the flow path distance of each gauge to the basin outlet.

- Disaggregated NEXRAD time-series data have been sampled by the eight fictitious rain gauges to obtain the gauge's time series.

- The tRIBS model parameters, including the soil parameters introduced previously, coming from the model calibration by Ivanov et al. (2004a), have been used for all the simulations. After simulation zero, precipitation fields which were derived from the rain gauge time series have been used to force the tRIBS model, for a total of 255 different simulations for each soil-type distribution and each event (resulting in 11,484 simulations). The 255 configurations result from all possible combinations of rain gauges.

To spatially distribute precipitation, the tRIBS model utilizes the Thiessen polygon method, which establishes regions of neighborhood around a point of observation. Any point inside each polygon assumes the observed values of the point of measurement used to construct the polygon. The primary advantage of this method is its simplicity. In addition to its simplicity, Tabios and Salas (1985), in a comparative analysis among different spatial interpolators, showed that Thiessen polygons gave fairly satisfactory results, even better than other more complex interpolation techniques as polynomial interpolation, and similar performances to inverse distance weighting method, especially in the case of very few rain gauges.

The flood hydrographs obtained for each simulation have been compared with the simulation zero. The performance of the network has been evaluated using the root-mean squared error (RMSE) as performance index. This index allows one to quantify the difference between the discharge (or precipitation) values obtained from the tRIBS model forced with the gauge precipitation and the true discharge (or precipitation) values. The RMSE has

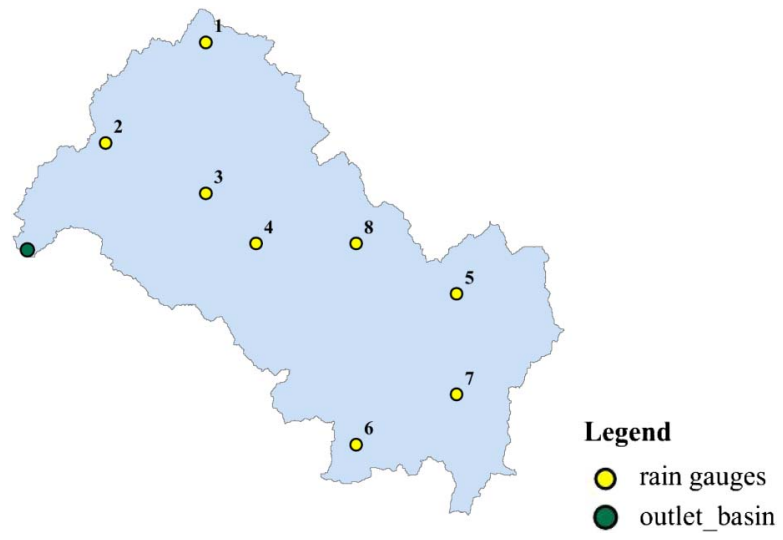

Fig. 4. Rain gauge placement inside the basin

been calculated by using the following formula for both the precipitation, $P$, and the discharge at the basin outlet, $Q$ :

$$
\operatorname{RMSE}_{X}=\sqrt{\frac{\sum_{i=1}^{N}\left(X_{i, \mathrm{GAU}}-X_{i, \mathrm{RAD}}\right)^{2}}{N}}
$$

where $X_{i, \mathrm{GAU}}=$ mean areal precipitation over the basin or the outlet discharge at time $i$, obtained from the tRIBS model forced with rain gauge measurements; $X_{i, \mathrm{RAD}}=$ "true" mean areal precipitation over the basin at time $i$ (i.e., that coming from the disaggregated radar data), or the outlet discharge at time $i$ obtained from tRIBS model forced with the true precipitation; and $N=$ event duration in hours, corresponding to the total number of hourly time step. To compare events characterized by different magnitudes, the normalized RMSE (NRMSE) is introduced by normalizing the RMSE by the average $X_{m}$ of observed data $\left(\mathrm{NRMSE}=\mathrm{RMSE} / X_{m}\right)$.

\section{Results and Discussion}

Analysis of results is carried out to identify the network configurations that best reconstruct either the rainfall field or the runoff estimation, in conjunction with the basin soil properties in the latter case. This is done by understanding which network, for a fixed number of rain gauges and soil-type distribution, minimizes the RMSE for precipitation $\left(\mathrm{RMSE}_{P}\right)$ and discharge $\left(\mathrm{RMSE}_{Q}\right)$.

\section{Rainfall Estimation}

The distribution of precipitation obtained for each combination of rain gauges has been compared with the true precipitation distribution coming from disaggregated NEXRAD. For a fixed number of rain gauges composing the network, that with the smallest $\mathrm{RMSE}_{P}$ $\left(\mathrm{RMSE}_{\min , P}\right)$ has been chosen as the best network for rainfall estimation. Clearly, such analysis is not influenced by the basin soil properties.

Table 3 summarizes the results for each event as a function of the number of gauges in the network. Networks with the

Table 2. Soil-Type Parameter

\begin{tabular}{lccccccc}
\hline Soil type & $n$ & $\theta_{s}\left(\mathrm{~mm}^{3} \mathrm{~mm}^{-3}\right)$ & $\theta_{r}\left(\mathrm{~mm}^{3} \mathrm{~mm}^{-3}\right)$ & $\psi_{b}(\mathrm{~mm})$ & $\lambda$ & $k_{s}(\mathrm{~mm} / \mathrm{h})$ & $f\left(\mathrm{~mm}^{-1}\right)$ \\
\hline Silty-clay & 0.475 & 0.36 & 0.07 & -370 & 0.15 & 1 & 0.0001 \\
Sandy-clay-loam & 0.437 & 0.39 & 0.01 & -73 & 0.592 & 100 \\
Loam & 0.463 & 0.40 & 0.009 & -110 & 0.254 & 235 & 0.001 \\
\hline
\end{tabular}

Note: $n=$ totalporosity; $\theta_{s}=$ soil moisture at saturation; $\theta_{r}=$ residual soil moisture; $\psi_{b}=$ air entry bubbling pressure; $\lambda=$ pore-size distribution index; $K_{s}=$ saturated hydraulic conductivity; $f=$ decay parameter of conductivity; and $A_{r}=$ anisotropy ratio. 
Table 3. RMSE $E_{\min , P}$ and Optimal Rain Gauge Network for a Fixed Number of Gauges for Each Event

\begin{tabular}{|c|c|c|c|c|c|c|}
\hline \multirow{2}{*}{$\begin{array}{l}\text { Number } \\
\text { of gauges }\end{array}$} & \multicolumn{2}{|c|}{ Event $\mathrm{Hh}$} & \multicolumn{2}{|c|}{ Event $\mathrm{Hm}$} & \multicolumn{2}{|c|}{ Event $\mathrm{Hl}$} \\
\hline & $\operatorname{RMSE}_{\min , P}(\mathrm{~mm} / \mathrm{h})$ & Gauges & $\mathrm{RMSE}_{\min , P}(\mathrm{~mm} / \mathrm{h})$ & Gauges & $\operatorname{RMSE}_{\min , P}(\mathrm{~mm} / \mathrm{h})$ & Gauges \\
\hline 1 & 0.946 & 4 & 0.964 & 8 & 1.655 & 8 \\
\hline 2 & 0.306 & 1,8 & 0.387 & 3,5 & 0.686 & 3,7 \\
\hline 3 & 0.179 & $1,5,8$ & 0.309 & $1,3,5$ & 0.487 & $2,4,7$ \\
\hline 4 & 0.169 & $1,5,6,8$ & 0.241 & $3,4,5,6$ & 0.342 & $2,4,6,7$ \\
\hline 5 & 0.170 & $1,5,6,7,8$ & 0.231 & $2,3,5,6,8$ & 0.302 & $2,4,5,6,7$ \\
\hline 6 & 0.261 & $1,4,5,6,7,8$ & 0.207 & $1,2,3,5,6,8$ & 0.271 & $2,3,4,5,6,7$ \\
\hline 7 & 0.339 & $2,3,4,5,6,7,8$ & 0.211 & $1,2,3,5,6,7,8$ & 0.267 & $2,3,4,5,6,7,8$ \\
\hline 8 & 0.421 & All & 0.219 & All & 0.323 & All \\
\hline \multirow{2}{*}{$\begin{array}{l}\text { Number } \\
\text { of gauges }\end{array}$} & \multicolumn{2}{|c|}{ Event Mh } & \multicolumn{2}{|c|}{ Event $\mathrm{Mm}$} & \multicolumn{2}{|c|}{ Event Ml } \\
\hline & $\operatorname{RMSE}_{\min , P}(\mathrm{~mm} / \mathrm{h})$ & Gauges & $\operatorname{RMSE}_{\min , P}(\mathrm{~mm} / \mathrm{h})$ & Gauges & $\operatorname{RMSE}_{\min , P}(\mathrm{~mm} / \mathrm{h})$ & Gauges \\
\hline 1 & 0.975 & 3 & 0.575 & 8 & 1.252 & 8 \\
\hline 2 & 0.754 & 3,7 & 0.162 & 1,8 & 0.400 & 3,5 \\
\hline 3 & 0.204 & $3,7,8$ & 0.100 & $3,6,8$ & 0.340 & $3,7,8$ \\
\hline 4 & 0.244 & $2,4,5,6$ & 0.107 & $2,3,6,8$ & 0.288 & $1,3,7,8$ \\
\hline 5 & 0.193 & $2,3,4,5,7$ & 0.114 & $1,2,3,6,8$ & 0.212 & $1,2,3,7,8$ \\
\hline 6 & 0.185 & $1,2,3,4,7,8$ & 0.183 & $1,2,3,4,6,8$ & 0.236 & $1,2,3,6,7,8$ \\
\hline 7 & 0.226 & $1,3,4,5,6,7,8$ & 0.342 & $1,2,3,4,5,7,8$ & 0.283 & $1,2,3,5,6,7,8$ \\
\hline 8 & 0.406 & All & 0.393 & All & 0.334 & All \\
\hline \multirow{2}{*}{$\begin{array}{l}\text { Number } \\
\text { of gauges }\end{array}$} & \multicolumn{2}{|c|}{ Event Lh } & \multicolumn{2}{|c|}{ Event Lm } & \multicolumn{2}{|c|}{ Event Ll } \\
\hline & $\operatorname{RMSE}_{\min , P}(\mathrm{~mm} / \mathrm{h})$ & Gauges & $\operatorname{RMSE}_{\min , P}(\mathrm{~mm} / \mathrm{h})$ & Gauges & $\operatorname{RMSE}_{\min , P}(\mathrm{~mm} / \mathrm{h})$ & Gauges \\
\hline 1 & 1.132 & 8 & 0.803 & 8 & 0.198 & 4 \\
\hline 2 & 0.556 & 3,8 & 0.338 & 7,8 & 0.126 & 4,8 \\
\hline 3 & 0.178 & $1,4,7$ & 0.236 & $2,3,5$ & 0.071 & $2,4,5$ \\
\hline 4 & 0.154 & $1,3,6,7$ & 0.165 & $2,3,7,8$ & 0.086 & $2,3,4,5$ \\
\hline 5 & 0.164 & $1,2,3,4,7$ & 0.166 & $1,2,3,7,8$ & 0.085 & $2,3,4,6,8$ \\
\hline 6 & 0.164 & $1,3,4,6,7,8$ & 0.164 & $1,2,3,5,7,8$ & 0.079 & $2,3,4,5,7,8$ \\
\hline 7 & 0.321 & $1,2,3,4,6,7,8$ & 0.197 & $2,3,4,5,6,7,8$ & 0.092 & $2,3,4,5,6,7,8$ \\
\hline 8 & 0.681 & All & 0.215 & All & 0.112 & All \\
\hline
\end{tabular}

Note: Networks with minimum $\mathrm{RMSE}_{\min , P}$ are highlighted in bold.

$\mathrm{RMSE}_{\min , P}$ are highlighted in bold. For each event, the $\mathrm{RMSE}_{\min , P}$ is not obtained with the complete network but with a fewer number of rain gauges. For example, in the event Ml, five gauges provided better precipitation estimations relative to the complete network. This behavior can be attributed to the addition of three rain gauges that sample precipitation lower than that measured by the initial five gauges, as well as the radar, producing an increase of the estimation. With an even higher number of gauges distributed in the basin, the $\mathrm{RMSE}_{P}$ should progressively decrease to a null value, theoretically achieved with a number of gauges equal to the disaggregated NEXRAD grid cells.

For example in event $\mathrm{Hh}$, if only one rain gauge is used, the lowest value of $\mathrm{RMSE}_{P}$ is obtained by Rain Gauge 4 that is placed in the center of the basin. If two rain gauges are used, the minimum $\mathrm{RMSE}_{P}$ is obtained with Gauges 1 and 8, placed downstream (Gauge 1) and upstream (Gauge 8), respectively. In the configuration with three rain gauges, the best network is comprised of Gauges 1, 5, and 8; whereas the four-gauge configuration is made up of Gauges 1, 5, 6, and 8, with three gauges upstream the basin and only one downstream because the precipitation is primarily distributed upstream. In the cases of five rain gauges, there are still four gauges upstream and one downstream. Therefore, the rain gauge position is strongly dependent on the precipitation spatial pattern.

By comparing all the events, the derivation of criteria to understand the best position of rain gauges for the estimation of precipitation is not easily achievable since the reconstruction of the rainfall volume is strongly influenced by the spatial pattern of precipitation, and the network performances vary for each event, as also stated by Lopes (1996).

However, some remarks can be made taking into account the nine events as a whole. For example, for a fixed number of gauges in the network, the percentage of occurrences at each rain gauge is plotted in Fig. 5. In the one-rain-gauge network, Gauge 8 is the most frequent and therefore the most influential. Varying the number of gauges in the networks, Gauges 3 and 8 are always included, whereas Gauges 1, 2, and 6 are the least influential to reconstruct the correct mean areal precipitation.

Results previously shown in Table 3 are summarized in Fig. 6, reporting the average $\mathrm{NRMSE}_{\min , P}$ values $\left(\overline{\mathrm{NRMSE}}_{\text {min }, P}\right)$ over the nine events as a function of the number of used gauges, making results independent of the rainfall event. If only one rain gauge is used, the $\overline{\mathrm{NRMSE}}_{\min , P}$ is obtained by Rain Gauge 8 that is placed in the central part of the basin. When two rain gauges are used, the $\overline{\text { NRMSE }}_{\text {min, } P}$ is achieved with Gauges 3 and 7, placed upstream (Gauge 7) and downstream (Gauge 3). In the configuration with three rain gauges, the best network is comprised of Gauges 3, 7 , and 8, whereas the four-gauge configuration includes Gauges $2,3,7$, and 8 . In this case, the best network is obtained with five gauges, three gauges downstream (Gauges 2, 3, and 4) and two upstream (Gauges 7 and 8); again, the least influent are Gauges 5 and 6.

In summary, the results described so far suggest two findings: (1) it is not possible to obtain a unique optimal network to well reproduce the precipitation volume for all the rainfall events; and (2) intensity of the precipitation event and its spatial variability 

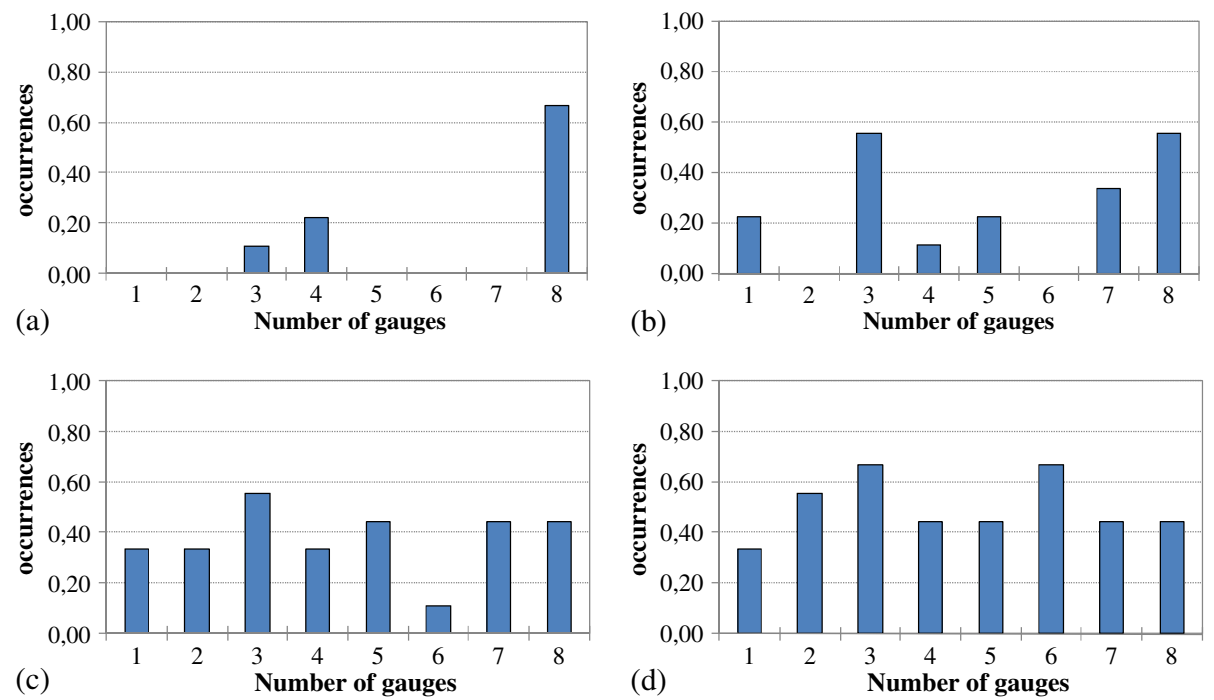

Fig. 5. Number of occurrences of each single rain gauge for precipitation estimation in the (a) one-rain-gauge network; (b) two-rain-gauge network; (c) three-rain-gauge network; (d) four-rain-gauge network

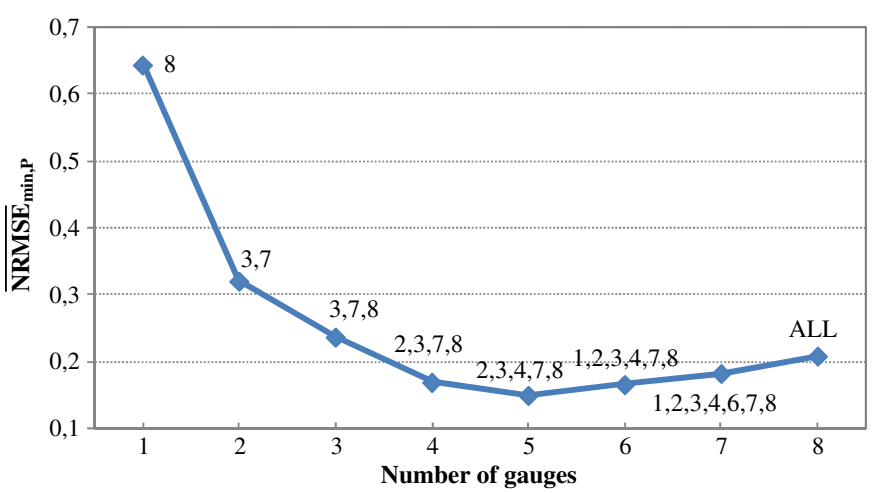

Fig. 6. Relationship between $\overline{\mathrm{NRMSE}}_{\mathrm{min}, P}$ and number of gauges for the average event

have significant influence on the design of the rain gauge network. These results are in agreement with Lopes (1996), who showed that the importance of the location of a gauge in describing the rainfall field may change with storm characteristics.

The interpolation method used to spatially distribute the precipitation also influences the results obtained in the analysis; further investigations by using different interpolation methods might indeed be interesting. However, the validity of Thiessen polygons method, widely used in many scientific works, does not disavow these results.

\section{Hydrograph Reconstruction}

In the case of runoff estimation, the search of the best network for a fixed number of rain gauges composing the network depends not only on the estimation of the true precipitation distribution but also on the rainfall-runoff transformation, which, in turn, depends on the distribution of the hydrological soil proprieties; as for the previous case, the best network is that with the smallest $\mathrm{RMSE}_{Q}$ $\left(\mathrm{RMSE}_{\min , Q}\right)$. The model structure used for the rainfall-runoff transformation (tRIBS model) may affect the results of such analysis. However, because it is a physically based scheme with distributed data and parameters, the simulation of the physical process is ensured; thus, the findings will not be strictly related to the model scheme used in this study.

The results have been evaluated by first analyzing the single events; then a summary of the overall analysis is also provided.

For the sake of brevity, the results of only two events, Hh and Lh, will be reported in this paper as an example of analysis carried out. Tables 4 and 5 show the optimal networks as a function of the soil-type configuration and the number of gauges in the network for events $\mathrm{Hh}$ and Lh, respectively (for a fixed soil-type distribution, the network with the minimum $\mathrm{RMSE}_{Q}$ is highlighted in bold). The $\operatorname{RMSE}_{Q}$ values associated to each best network are shown.

The first important observation arises by comparing the best networks obtained for the estimation of either precipitation (see events Hh and Lh of Table 3) or discharge (Tables 4 and 5). The configurations of the two types of networks rarely coincide, in agreement with Eagleson (1967a, b) and Faurès et al. (1995), because the best positions for the estimation of runoff are influenced by the rainfallrunoff transformation and thus by the soil distribution. As already observed for the estimation of the precipitation, the minimum $\mathrm{RMSE}_{Q}$ is never obtained with the complete network.

Event Hh (Table 4) is characterized by higher precipitation upstream. The lowest value of $\mathrm{RMSE}_{Q}$ is obtained by Rain Gauge 5, for the soil configurations c and cs. Instead, for s, sc, and r, the best is Rain Gauge 7. In particular, the best single rain gauge is placed in the area with higher precipitation. If two rain gauges are used, the best $\mathrm{RMSE}_{Q}$ is obtained with an upstream rain gauge and a downstream rain gauge for soil configurations $\mathrm{c}$ and sc, and with two upstream gauges for $\mathrm{s}$, cs, and $\mathrm{r}$. In the three-rain-gauge configuration, two rain gauges have to be located downstream in the basin (Gauges 1 and 4) and one rain gauge upstream (Gauge 8) in all soil configurations. In a network with four rain gauges, there are always two gauges upstream and two rain gauges downstream. The number of rain gauges placed upstream is usually greater than the number of rain gauges located downstream because of the spatial pattern of precipitation. Analysis of the network with more than four gauges is not worthy because a clear criterion for the best position of other gauges is not evident.

Event Lh (Table 5) is characterized by low intensity and high variability (higher precipitation upstream and lower rainfall downstream). With a single rain gauge and when the less permeable soil is upstream the basin ( $\mathrm{sc}$ ), the best network is with the rain gauge 
Table 4. RMSE $E_{\min , Q}$ and Optimal Network for a Fixed Number of Gauges for Each Soil Distribution and for Event Hh

\begin{tabular}{|c|c|c|c|c|c|c|c|c|c|c|}
\hline \multicolumn{6}{|c|}{$\operatorname{RMSE}_{\min , Q}\left(\mathrm{~m}^{3} / \mathrm{s}\right)$} & \multicolumn{5}{|c|}{ Rain gauges } \\
\hline $\begin{array}{l}\text { Number of } \\
\text { gaugeslsoil }\end{array}$ & $\mathrm{s}$ & $\mathrm{c}$ & $\mathrm{sc}$ & $\mathrm{cs}$ & $\mathrm{r}$ & $\mathrm{s}$ & $\mathrm{c}$ & $\mathrm{sc}$ & cs & $\mathrm{r}$ \\
\hline 1 & 0.464 & 1.387 & 0.989 & 0.848 & 0.837 & 7 & 5 & 7 & 5 & 7 \\
\hline 2 & 0.397 & 0.982 & 0.758 & 0.882 & 0.705 & 5,6 & 4,8 & 4,8 & 5,7 & 5,6 \\
\hline 3 & 0.328 & 0.662 & 0.568 & 0.556 & 0.470 & $1,4,8$ & $1,4,8$ & $1,4,8$ & $1,4,8$ & $1,4,8$ \\
\hline 4 & 0.308 & 0.768 & 0.419 & 0.552 & 0.442 & $1,4,6,8$ & $1,4,6,8$ & $2,3,6,8$ & $1,4,6,8$ & $1,4,6,8$ \\
\hline 5 & 0.380 & 1.026 & 0.438 & 0.645 & 0.587 & $1,4,6,7,8$ & $1,4,6,7,8$ & $1,2,3,6,8$ & $1,4,6,7,8$ & $1,2,3,4,8$ \\
\hline 6 & 0.382 & 1.157 & 0.544 & 0.707 & 0.564 & $1,2,3,4,6,8$ & $1,2,3,4,6,8$ & $1,2,3,4,6,8$ & $1,4,5,6,7,8$ & $1,2,3,4,6,8$ \\
\hline 7 & 0.423 & 1.175 & 0.788 & 1.124 & 0.674 & $1,2,3,4,6,7,8$ & $1,2,3,4,6,7,8$ & $1,2,3,4,6,7,8$ & $1,2,3,4,5,6,7$ & $1,2,3,4,6,7,8$ \\
\hline 8 & 0.477 & 1.323 & 1.139 & 1.152 & 0.828 & & & All & & \\
\hline
\end{tabular}

Note: Networks with minimum $\operatorname{RMSE}_{\min , Q}$ are highlighted in bold.

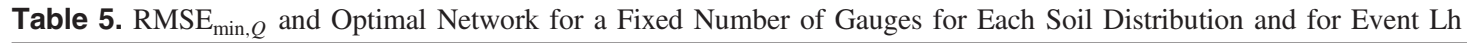

\begin{tabular}{|c|c|c|c|c|c|c|c|c|c|c|}
\hline \multicolumn{6}{|c|}{$\operatorname{RMSE}_{\min , \mathrm{Q}}\left(\mathrm{m}^{3} / \mathrm{s}\right)$} & \multicolumn{5}{|c|}{ Rain gauges } \\
\hline $\begin{array}{l}\text { Number of } \\
\text { gaugeslsoil }\end{array}$ & $\mathrm{s}$ & $\mathrm{c}$ & $\mathrm{sc}$ & $\mathrm{cs}$ & $\mathrm{r}$ & $\mathrm{s}$ & $\mathrm{c}$ & $\mathrm{sc}$ & $\mathrm{cs}$ & $\mathrm{r}$ \\
\hline 1 & 2.490 & 5.483 & 3.997 & 2.701 & 3.501 & 2 & 7 & 7 & 2 & 2 \\
\hline 2 & 1.466 & 3.409 & 3.244 & 1.799 & 2.041 & 7,8 & 2,7 & 2,7 & 7,8 & 2,7 \\
\hline 3 & 1.131 & 2.074 & 2.119 & 1.333 & 1.681 & $1,2,7$ & $5,7,8$ & $5,7,8$ & $1,2,7$ & $5,7,8$ \\
\hline 4 & 1.208 & 2.280 & 2.136 & 1.384 & 1.777 & $1,2,3,7$ & $2,5,7,8$ & $1,5,7,8$ & $1,2,3,7$ & $1,5,7,8$ \\
\hline 5 & 1.113 & 1.937 & 1.910 & 1.148 & 1.363 & $1,2,5,7,8$ & $1,3,5,7,8$ & $1,2,5,7,8$ & $1,3,5,7,8$ & $1,2,5,7,8$ \\
\hline 6 & 1.179 & 1.937 & 1.966 & 1.133 & 1.436 & $1,2,3,5,7,8$ & $1,2,3,5,7,8$ & $1,2,3,5,7,8$ & $1,2,3,5,7,8$ & $1,2,3,5,7,8$ \\
\hline 7 & 1.293 & 2.188 & 2.207 & 1.238 & 1.574 & $1,2,3,5,6,7,8$ & $1,2,3,5,6,7,8$ & $1,2,3,5,6,7,8$ & $1,2,3,5,6,7,8$ & $1,2,3,5,6,7,8$ \\
\hline 8 & 1.636 & 2.663 & 2.481 & 1.875 & 2.020 & & & All & & \\
\hline
\end{tabular}

Note: Networks with minimum $\operatorname{RMSE}_{\min , Q}$ are highlighted in bold.

placed upstream (Gauge 7), whereas if the less permeable soil is downstream in the basin (cs), the best network is with the rain gauge placed downstream (Gauge 2). In a three-rain-gauge network, the gauges are located upstream (Gauges 5, 7, 8) for c and sc soil configurations, whereas in the case of cs configuration, two gauges are placed downstream (Gauges 1 and 2) and a gauge upstream (Gauge 7). The observed pattern points out that the usual location of the rain gauges in the soils is characterized by low permeability.

A similar analysis was performed for the other seven events. Further observations can be made by assessing how the different combinations of rainfall characteristics to soil-type distributions may affect the network design and by evaluating which is the most influential feature.

In the described event $\mathrm{Hh}$, the single rain gauge is placed where the precipitation is higher. If the average precipitation intensity is medium but the spatial variability of rainfall is still high (this is the case of event Mh, not described in this paper), the influence of precipitation pattern is more considerable than that of soil-types distribution, and the single gauge is placed where the precipitation is higher. In the previously described event Lh, the single gauge is placed where the soil is less permeable because the effect of the less permeable soil position seems to prevail on the effect of precipitation distribution. If the spatial variability of precipitation is low (events Hl-Ml-Ll), then the gauge's position seems to not be influenced by the soil distribution, and the best network is obtained with the same number of gauges for all the soil configurations. Moreover, if the spatial variability of precipitation is medium (events Mm-Lm), the soil-type distribution plays a minor role on the position of the gauges.

The overall results and observations point out that the factors that may influence the distribution of rain gauges for the runoff estimation are: (1) soil-type distribution, with a general trend to locate the rain gauges where the soil is less permeable; and (2) precipitation spatial distribution, with the rain gauges placed where precipitation is higher.

To compare the different events, the previously defined $\mathrm{NRMSE}_{Q}$ has been used. Fig. 7 shows the value of $\mathrm{NRMSE}_{\min , Q}$ for each event as a function of the number of gauges and for fixed soil configuration. When rainfall spatial variability is high (events Hh-Mh-Lh), there is an increased influence of the soil configuration on the network performance, and the gauge location becomes a crucial parameter in modeling the storm hydrograph, as also stated by Faurès et al. (1995). For medium or low $\mathrm{COV}_{S}$, as the soil configuration changes, the $\mathrm{NRMSE}_{\min , Q}$ curves have a similar pattern.

For event $\mathrm{Hl}$ and varying the soil distribution, the curves do not have a similar pattern, and the soil distribution influences the design of the best network. When spatial variability of rainfall is low, the distribution of rain gauges varies little, changing the soil distribution; one can observe a flattening of the $\mathrm{NRMSE}_{\min , Q}$ curves, and then the position of the gauges seems to be not influenced by the soil distribution (events Hl-Ml-Ll). The best network is obtained with the same number of gauges for all the soil configurations.

For a fixed number of gauges in the network, the percentage of occurrences of a single rain gauge in the best network as a function of the soil configuration is observed and analyzed in Fig. 8. In the one-rain-gauge network [Fig. 8(a)], Gauge 6 is never present, Gauge 3 is the most influential in the soil configuration cs, whereas Gauge 5 is recurrent in sc (occurrence equal to 0.56), and Gauges 1, 2 , and 4 are never present in sc.

Varying the number of gauges in the networks, Gauges 3 and 5 are always present, whereas Gauges 2, 4, and 6 are less frequent; Gauge 8 is usually present, maintaining the same frequency when varying the soil distribution. Gauges 1 and 7, less important in the networks with one or two gauges, become more recurrent in the 

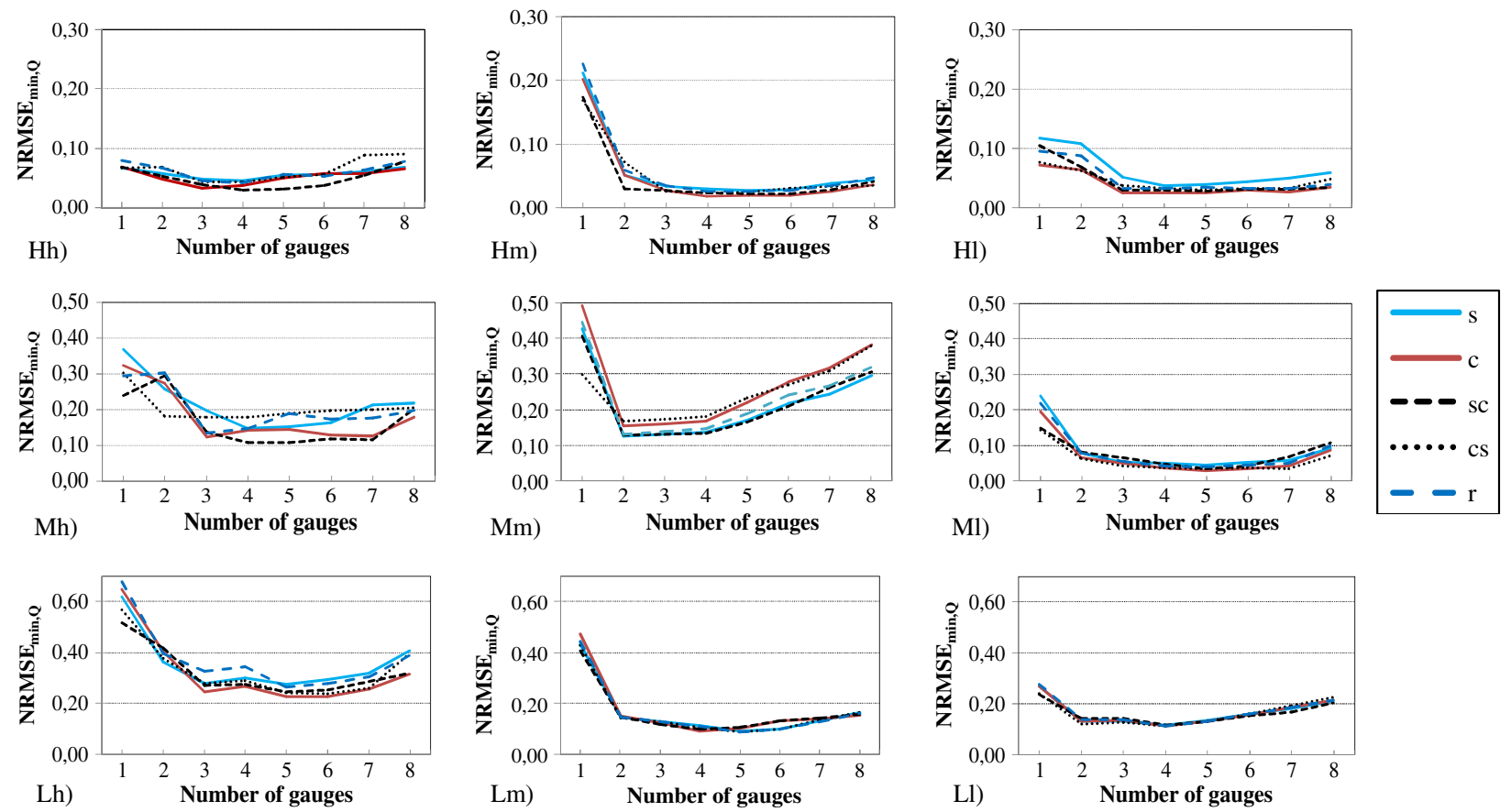

Fig. 7. NRMSE $\mathrm{E}_{\min , Q}$ as a function of the number of gauges for each soil configuration and each event
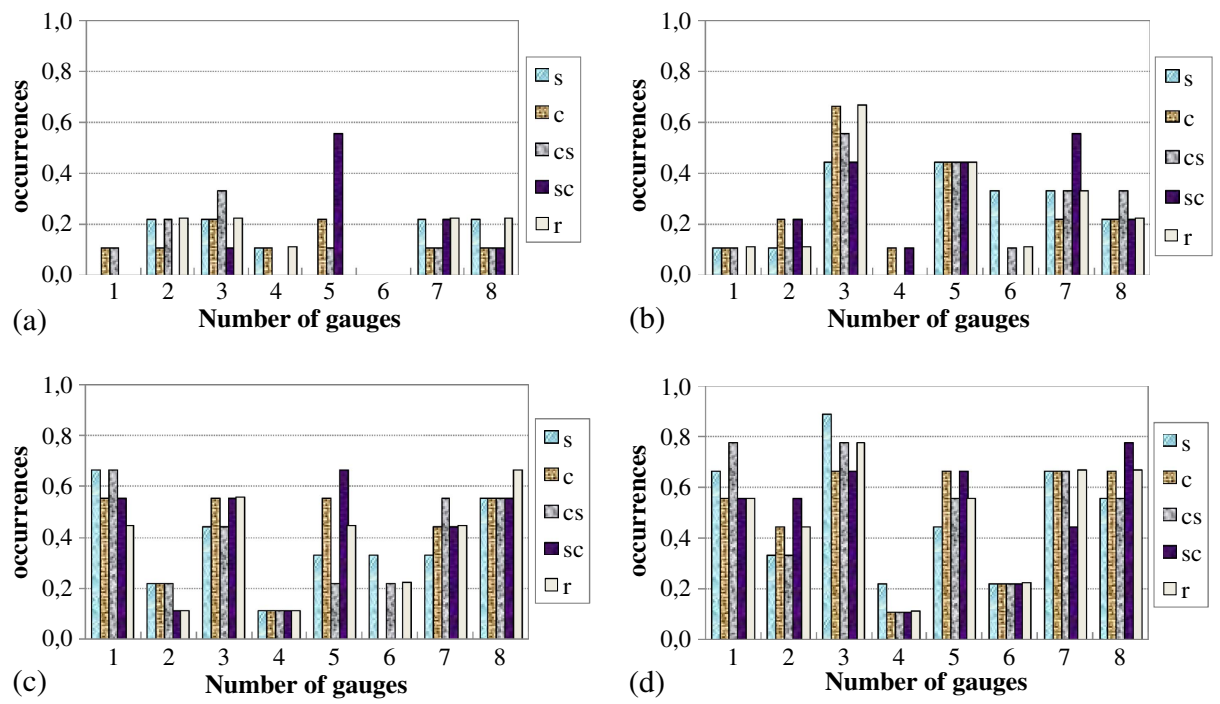

Fig. 8. Number of occurrences of each single rain gauge in the network as a function of the soil configuration in the case of runoff estimation: (a) one gauge; (b) two gauges; (c) three gauges; (d) four gauges

network with three and four gauges. When a single rain gauge is used in cs, the best rain gauge is placed downstream for six events and upstream for three events; whereas in sc the gauge is upstream for eight events and downstream only for one event. This observed pattern confirms again that the best single rain gauge tends to be located in areas characterized by low permeability.

All the results previously shown are summarized in Table 6 by averaging the $\mathrm{NRMSE}_{\text {min, },}$ over the nine events $\left(\overline{\mathrm{NRMSE}}_{\min , Q}\right)$. The best network for average conditions seems not to be influenced by the soil-type distribution because the network composition is almost the same for each soil-type distribution. This behavior is probably attributable to the removal of the influence of the spatial pattern of the precipitation by averaging the results relative to each event.

As the number of rain gauges increases, there is no clear criterion for the best positioning of a new gauge. However, when there are three or five gauges in the network, there is no influence of the soil distribution, and the network is about the same for each soil distribution.

The same analysis carried out for the hydrograph reconstruction has been performed also comparing the hydrograph peak obtained with the precipitation measured by rain gauge networks and the true hydrograph peak (obtained with the precipitation measured by radar) for each event. Performance of the networks has been 
Table 6. $\overline{\mathrm{NRMSE}}_{\min , Q}$ and Best Network as a Function of the Number of Gauges and for Fixed Soil Distribution

\begin{tabular}{|c|c|c|c|c|c|c|c|c|c|c|c|}
\hline \multicolumn{6}{|c|}{$\operatorname{NRMSE}_{Q}\left(\mathrm{~m}^{3} / \mathrm{s}\right)$} & \multicolumn{5}{|c|}{ Rain gauges } & \multirow[b]{2}{*}{$\mathrm{NRMSE}_{P}$} \\
\hline $\begin{array}{l}\text { Number of } \\
\text { gaugesisoil }\end{array}$ & $\mathrm{s}$ & $\mathrm{c}$ & $\mathrm{sc}$ & $\mathrm{cs}$ & $\mathrm{r}$ & $\mathrm{s}$ & $\mathrm{c}$ & $\mathrm{sc}$ & cs & $\mathrm{r}$ & \\
\hline 1 & 0.416 & 0.451 & 0.429 & 0.347 & 0.447 & 3 & 3 & 8 & 3 & 3 & 8 \\
\hline 2 & 0.248 & 0.279 & 0.257 & 0.237 & 0.271 & 3,7 & 3,7 & 7,8 & 3,8 & 3,7 & 3,7 \\
\hline 3 & 0.175 & 0.192 & 0.175 & 0.188 & 0.174 & $3,7,8$ & $3,7,8$ & $3,7,8$ & $3,7,8$ & $3,7,8$ & $3,7,8$ \\
\hline 4 & 0.153 & 0.154 & 0.136 & 0.175 & 0.158 & $2,3,7,8$ & $3,5,7,8$ & $3,5,7,8$ & $1,3,7,8$ & $3,5,7,8$ & $2,3,7,8$ \\
\hline 5 & 0.138 & 0.148 & 0.134 & 0.151 & 0.145 & $1,3,5,7,8$ & $1,3,5,7,8$ & $1,3,5,7,8$ & $1,3,5,7,8$ & $1,3,5,7,8$ & $2,3,4,7,8$ \\
\hline 6 & 0.142 & 0.155 & 0.138 & 0.164 & 0.152 & $1,2,3,5,7,8$ & $1,2,3,5,7,8$ & $1,2,3,5,7,8$ & $1,3,5,6,7,8$ & $1,2,3,5,7,8$ & $1,2,3,4,7,8$ \\
\hline 7 & 0.150 & 0.160 & 0.152 & 0.174 & 0.163 & $1,2,3,5,6,7,8$ & $1,2,3,4,5,7,8$ & $1,2,3,5,6,7,8$ & $1,2,3,5,6,7,8$ & $1,2,3,5,6,7,8$ & $1,2,3,4,6,7,8$ \\
\hline 8 & 0.174 & 0.163 & 0.161 & 0.180 & 0.173 & & & All & & & All \\
\hline
\end{tabular}

Note: Networks with minimum $\overline{\mathrm{NRMSE}}_{\min , Q}$ are highlighted in bold. The last column shows the precipitation best network.

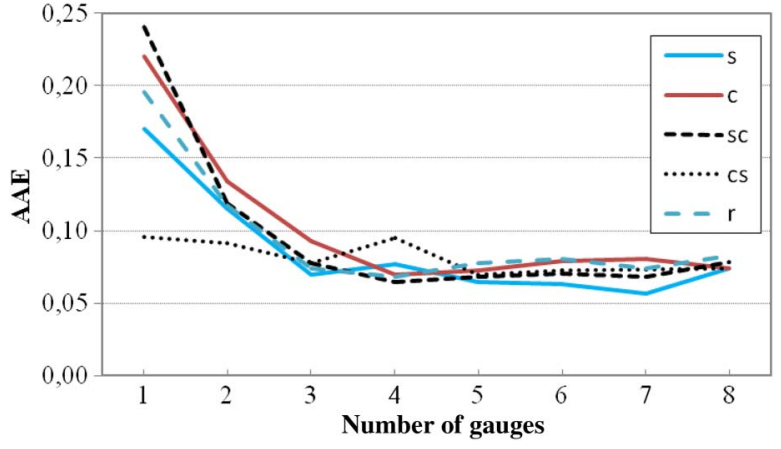

Fig. 9. Event AAE as a function of the number of gauges for each soil configuration

evaluated calculating the nondimensional absolute error for each event

$$
A E=\frac{\left|Q_{P, \mathrm{GAU}}-Q_{P, \mathrm{RAD}}\right|}{Q_{P, \mathrm{RAD}}}
$$

where $Q_{P, \mathrm{GAU}}=$ flow peak of the event resulting from model response forced with the precipitation measured by the best networks obtained from the analysis of the $\mathrm{NRMSE}_{\min , Q}$ averaged over the nine events, as described in Table 6; and $Q_{P, \mathrm{RAD}}=$ flow peak resulting from model response forced with the true precipitation distribution.

Results are analyzed considering the curve of average absolute error (AAE), obtained as average of the $\mathrm{AE}$ over the nine events as a function of the number of gauges for each soil configuration (Fig. 9).

As already observed, in comparison with the best network for estimation of runoff, it comes out again that the best network for estimation of the hydrograph rarely coincides with the best network for the estimation of the hydrograph peak. Comparing results from Table 6 (network finalized to hydrograph reconstruction) with those of Fig. 9 (network finalized to hydrograph peak estimation) shows that the minimum of curves for each soil type is different, and the optimal network is obtained with a different number of gauges.

The event scale findings have been verified by continuous model simulation for 1 year (1998) using $r$ soil-type configuration. Results of the simulation confirmed the most important findings of the analysis at event scale, in agreement with Bardossy et al. (2008). Fig. 10 shows the $\mathrm{RMSE}_{\min , Q}$ as a function of the number of used gauges for the soil configuration $r$. Unlike the event scale case (Table 6), the minimum $\mathrm{RMSE}_{\min , Q}$ is obtained with the complete network, as found also in Obled et al. (1994). In fact, because

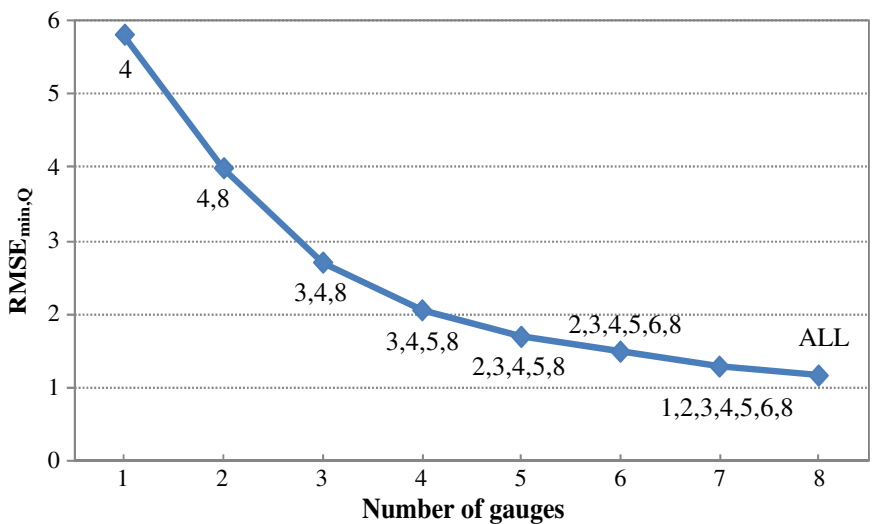

Fig. 10. Relationship between $\operatorname{RMSE}_{\min , Q}$ and number of gauges for the continuous simulation and soil configuration $r$

the continuous simulation contains many events with different intensity and spatial pattern, the influence of spatial pattern of the precipitation of each single events is probably removed. Moreover, the interstorm period is also considered in the evaluation of the network performances.

\section{Conclusions}

In this paper, a thorough investigation of the influence of rain gauge network characteristics on hydrological response at the catchment scale has been carried out. The use of a physically based, distributed hydrologic model (tRIBS) has allowed us to investigate the influence of rain gauge network configuration in terms of number and spatial distribution, on the estimation of precipitation and flood hydrograph in the Baron Fork Basin by taking into account the role of different soil properties. Analysis has been performed at the event scale by considering nine rainfall events with different spatial variability and intensity and different soil-type distribution.

Complexity of the relationship between the number of variables involved, particularly between rainfall volume and the nonlinear rainfall-runoff transformation, makes the issue very difficult to discuss. By analyzing the results from different points of view, the primary findings of the study can be summarized as follows:

- Comparison of structures of the best networks obtained in the different analysis points out that networks designed for the best reconstruction of rainfall field rarely coincide with the network designed for the best flood hydrograph reconstruction or for estimation of the hydrograph peak. This behavior confirms the results found by previous studies and is justified by the fact that 
the best gauge position for runoff estimation is also influenced by the rainfall-runoff transformation, which in turn depends on the soil-type distribution.

- Spatiotemporal characteristics of storm events have demonstrated a significant influence on catchment response predictions; and for a fixed event, the best rain gauge configurations for the runoff estimation are strongly dependent on the soil-type distribution. However, it is not possible to generalize the results obtained in a basin and to extend them to other basins because of the strong influence of the soil-type distribution. This conclusion is only valid for the runoff prediction and is subject to the particular combination of the precipitation spatial distribution scheme. The primary factors that influence the ideal position of rain gauges for improved streamflow prediction can be identified by the precipitation spatial distribution (i.e., the rain gauges are placed where higher precipitation occur) and soil-type distribution (i.e., general trend to locate the rain gauges where the soil is less permeable). Particularly (1) when the spatial variability of precipitation is high, the position of gauges becomes very important for modeling the storm hydrograph, and the greater the precipitation spatial gradient, the more significant is the effect of the soil type; and (2) when the rainfall spatial variability is low, the distribution of rain gauges varies little with the change of the distribution of soils. For these cases, the position of the gauges seems to not be influenced by the soil distribution and the best network is obtained with the same number of gauges for all the soil configurations.

From the preceding observations, the impossibility to create a single criterion for designing the best rain gauge network for the runoff estimation becomes clear. The choice of the best network is strongly dependent not only on the rainfall and soil-type characteristics (i.e., physical phenomena) but also on the type of output variable estimated by the hydrological model [i.e., either precipitation or total volume runoff or peak discharge or other variables (not investigated in this paper) such as soil moisture]. Moreover, because the reconstruction of the precipitation field depends on the used rainfall interpolated method, the use of the Thiessen polygon method might have influenced the model results but not disavowed their validity. Similar observations arise for the use of the specific structure implemented in the tRIBS model; however, because the scheme adopted by this model is physically based, the final results could be only slightly affected by the model structure, confirming the dependence of the best rain gauge network on the soil proprieties distribution.

\section{References}

Arnaud, P., Bouvier, C., Cisneros, L., and Dominguez, R. (2002). "Influence of rainfall spatial variability on flood prediction." J. Hydrol., 260(1-4), 216-230.

Bardossy, A., and Das, T. (2008). "Influence of rainfall observation network on model calibration and application." Hydrol. Earth Syst. Sci., 12(1), 77-89.

Bardossy, A., and Plate, E. (1992). "Space-time model for daily rainfall using atmospheric circulation patterns." Water Resour. Res., 28(5), $1247-1259$

Bell, V. A., and Moore, R. J. (2000). "The sensitivity of catchment runoff models to rainfall data at different spatial scales." Hydrol. Earth Syst. Sci., 4(4), 653-667.
Eagleson, P. S. (1967a). "A distributed linear model for peak catchment discharge." Proc., Int. Hydrology Symp., Vol. 1, Colorado State Univ., Fort Collins, CO, 1-8.

Eagleson, P. S. (1967b). "Optimum density of rainfall networks." Water Resour. Res., 3(4), 1021-1033.

Eagleson, P. S., and Shack, W. J. (1966). "Some criteria for the measurement of rainfall and runoff." Water Resour. Res., 2(3), 427-436.

Faurès, J. M., Goodrich, D. C., Woolhiser, D. A., and Sorooshian, S. (1995). "Impact of small-scale spatial rainfall variability on runoff modeling." J. Hydrol., 173(1-4), 309-326.

Ivanov, V. Y., Vivoni, E. R., Bras, R. L., and Entekhabi, D. (2004a). "Catchment hydrologic response with a fully-distributed triangulated irregular network model." Water Resour. Res., 40(11), W11102.

Ivanov, V. Y., Vivoni, E. R., Bras, R. L., and Entekhabi, D. (2004b). "Preserving high-resolution surface and rainfall data in operationalscale basin hydrology: A fully-distributed physically-based approach." J. Hydrol., 298(1-4), 80-111.

Krajewski, W. F., Ciach, G. J., and Habib, E. (2003). "An analysis of small-scale rainfall variability in different climatic regimes." Hydrol. Sci. J., 48(2), 151-162.

Krajewski, W. F., Lakshmi, V., Georgakakos, K. P., and Jain, S. C. (1991). "A Monte-Carlo study of rainfall sampling effect on a distributed catchment model." Water Resour. Res., 27(1), 119-128.

Liuzzo, L., Noto, L. V., Vivoni, E. R., and La Loggia, G. (2010). "Basin-scale water resources assessment in Oklahoma under synthetic climate change scenarios using a fully distributed hydrological model." J. Hydrol. Eng., 10.1061/(ASCE)HE.1943-5584.0000166, $107-122$.

Lopes, V. L. (1996). "On the effect of uncertainty in spatial distribution of rainfall on catchment modeling." Catena, 28(1-2), 107-119.

Meselhe, E. A., Habib, E. H., Oche, O. C., and Gautam, S. (2009). "Sensitivity of conceptual and physically based hydrologic models to temporal and spatial rainfall sampling." J. Hydrol. Eng., 10.1061/ (ASCE)1084-0699(2009)14:7(711), 711-720.

Noto, L. V., Ivanov, V. Y., Bras, R. L., and Vivoni, E. R. (2008). "Effects of initialization on response of a fully-distributed hydrologic model." J. Hydrol., 352(1-2), 107-125.

Obled, C., Wedling, J., and Beven, K. (1994). "The sensitivity of hydrological models to spatial rainfall patterns: An evaluation using observed data." J. Hydrol., 159(1-4), 305-333.

Perica, S., and Foufoula-Georgiou, E. (1996). "A model for multiscale disaggregation of spatial rainfall based on coupling meteorological and scaling descriptions." J. Geophys. Res., 101(D21), 26347-26361.

Schuurmans, J. M., and Bierkens, M. F. P. (2007). "Effect of spatial distribution of daily rainfall on interior catchment response of a distributed hydrological model." Hydrol. Earth Syst. Sci., 11(2), 677-693.

St-Hilarie, A., Ouarda, T. B. M. J., Lachance, M., Bobèe, B., Gaudet, J., and Gibnac, C. (2003). "Assessment of the impact of meteorological network density on the estimation of basin precipitation and runoff: a case study." Hydrol. Process., 17(18), 3561-3580.

Sun, H., Cornish, P. S., and Daniell, T. M. (2002). "Spatial variability in hydrologic modeling using rainfall-runoff model and digital elevation model." J. Hydrol. Eng., 10.1061/(ASCE)1084-0699(2002)7:6(404), 404-412.

Tabios, G. Q., and Salas, J. D. (1985). "A comparative analysis of techniques for spatial interpolation of precipitation." Water Resour. Bull., 21(3), 365-380.

Vivoni, E. R., et al. (2006). "Extending the predictability of hydrometeorological flood events using radar rainfall nowcasting." J. Hydrometeorol., 7(4), 660-677.

Wilson, C. B., Valdes, J. B., and Rodriguez-Iturbe, I. (1979). "On the influence of the spatial distribution of rainfall on storm runoff." Water Resour. Res., 15(2), 321-328. 